\title{
Modified technique of managing congenital cataract with pre-existing posterior capsular defect (PPCD)
}

\author{
Sudarshan Khokhar, ${ }^{1}$ Mousumi Banerjee (1) , ${ }^{1,2}$ Sanketh Singh Rathod, ${ }^{2}$ Sushil Kumar ${ }^{2}$
}

'Ophthalmology, All India Institute of Medical Sciences, New Delhi, Delhi, India ${ }^{2} \mathrm{RPC}$, All India Institute of Medical Sciences, New Delhi, Delhi, India

\section{Correspondence to} Dr Mousumi Banerjee; banerjeemou12@gmail.com

Accepted 22 April 2021
Check for updates

(c) BMJ Publishing Group Limited 2021. No commercial re-use. See rights and permissions. Published by BMJ.

\footnotetext{
To cite: Khokhar S, Banerjee M, Rathod SS, et al. BMJ Case Rep 2021;14:e243330. doi:10.1136/bcr-2021243330
}

\section{DESCRIPTION}

Congenital cataract with pre-existing posterior capsule defect (PPCD) is a rare condition with an incidence ranging from $2 \%$ to $6.7 \% .^{12}$ The most common hypothesis of PPCD is the presence of pre-existing posterior lenticonus and its subsequent thinning which leads to microleaks and rapid maturation of the cataract leading to further thinning and formation of posterior capsular defect. ${ }^{2}$

Surgical management in paediatric cataract with PPCD remains a challenge due to the increased risk of lens matter drop in the vitreous cavity. We present a modified approach of managing such challenging situations with preoperative ultrasound biomicroscopy (UBM) and 'dry lens aspiration technique' through limbal route .

Three types of PPCD have been described in literature based on the morphology of the posterior capsular defect. Type 1 is depicted by welldefined posterior capsular defect, with sharp edges and minimal fibrosis. Type 2 is characterised by circular or regular defect with fibrosis and type 3 has a posterior capsular plaque which seals off the defect. $^{3}$ The most common type of PPCD observed in our cases was type 1 . All our cases were found to have PPCD on UBM imaging, while majority were missed out on B scan ultrasonography.

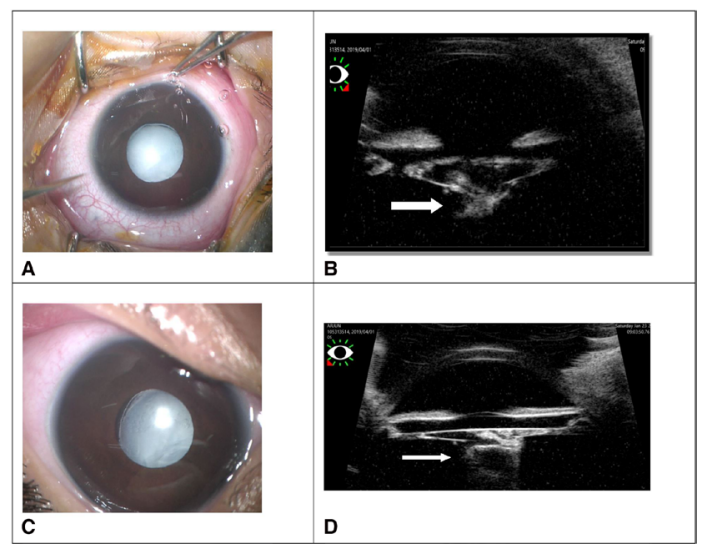

Figure 1 A clinical photograph of total nuclear cataract od in a 8-month-old child seen during examination under anaesthesia with absorption of lens matter in some areas (A) with the corresponding ultrasound biomicroscopy (UBM) depicting a posterior capsular defect with lens matter behind the posterior capsule (white arrow) in (B). Clinical photograph of total nuclear cataract oculus sinister (OS) in a 9-month-old child with deepened anterior chamber and absorption of lens matter (C) with a posterior capsular defect, flattened anterior capsule and loss of lens volume depicted on UBM (D).

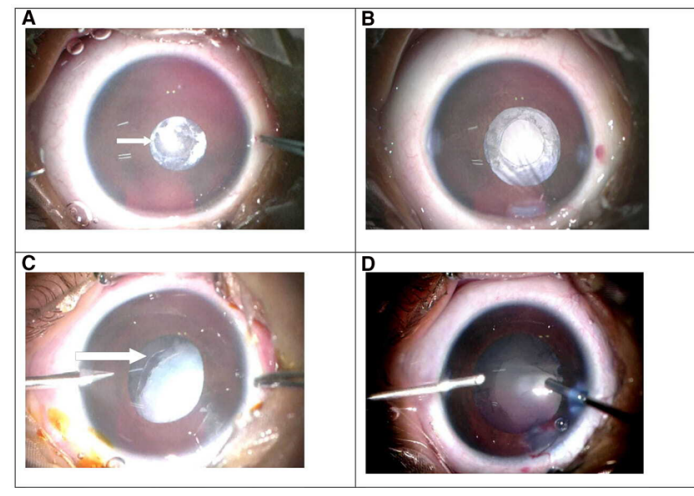

Figure 2 Clinical picture of type 2 posterior capsule defect (PCD) in a 8-month-old chid with significant loss of lens volume $(A)$ better appreciated after lens aspiration with circular, regular margins of type 2 PCD (B) clinical picture of type 1 PCD in a 9-month-old child with nuclear cataract (C) better appreciated after lens aspiration with oval, regular margins of type 1 PCD with minimal fibrosis (D).

Figure 1A-D depicts the clinical pictures with corresponding UBM findings in our patients with PPCD.

Figure 2A-D depicts the type 1 and 2 variants of PPCD observed in our patients.

Surgical technique: Three incisions were made using microvitreoretinal blade, followed by staining of the anterior capsule using $0.06 \%$ trypan blue dye under air. Safety profile of trypan blue dye in paediatric cataract surgery has been verified in various studies which describes the role of trypan blue to facilitate higher success rate of completion of manual capsulorhexis by decreasing the elasticity of the lens capsule. ${ }^{45}$ Anterior continuous curvilinear capsulorhexis (CCC) was performed with longer microincision forceps (for better anterior chamber (AC) stability) as depicted in figure 3A. Anterior capsulectomy (vitrectorhexis) is an alternative well known method to perform capsulorhexis. However, vitrectorhexis has an increased propensity of radial tears and edges are less smooth than that produced by manual CCC. ${ }^{6}$ Hydrodissection was avoided in all the cases to prevent extension of the pre-existing defect and lens matter drop posteriorly.

Lens aspiration was performed with Centurion vision system using active fluidics technology with $25 \mathrm{G}$ anterior vitrectomy cutter through the side port in irrigation-aspiration/cut mode (I-A cut mode) without insertion of the irrigation probe inside the AC. Low flow rate and low intraocular pressure (IOP) settings were kept than that used in routine paediatric cases to prevent turbulence and collapse 


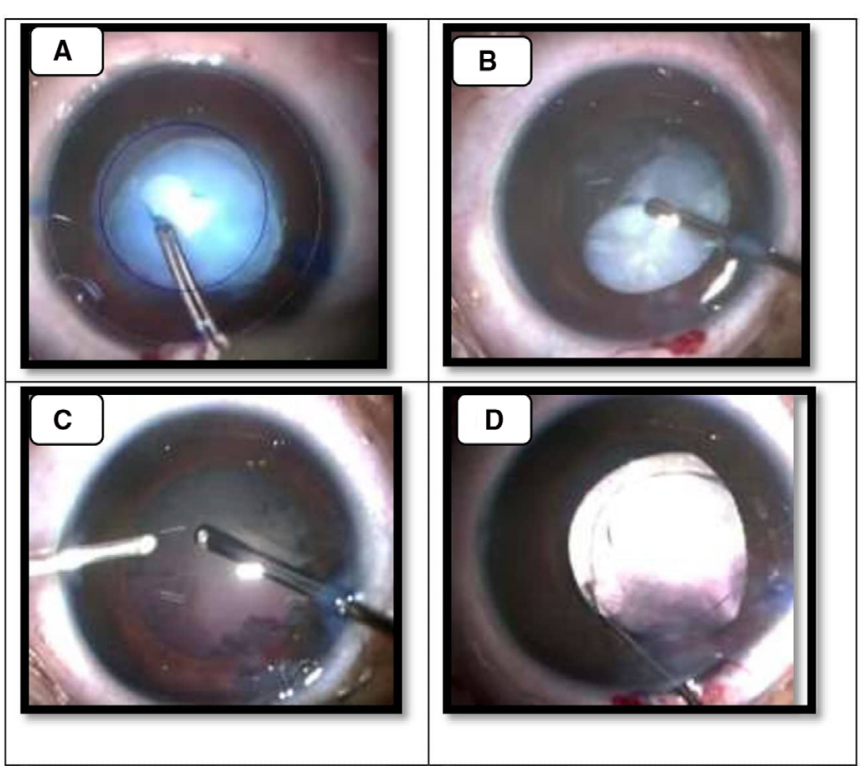

Figure 3 Depicts the surgical steps of lens aspiration using our technique. (A) demonstrates anterior continuous curvilinear capsulorhexis after staining of the anterior capsule with $0.06 \%$ trypan blue dye, followed by lens aspiration with $25 \mathrm{G}$ vitrectomy cutter in irrigation-aspiration/cutter mode without insertion of the irrigation probe as depicted in (B) irrigation probe is inserted into the anterior chamber once three-fourth of the volume of the lens is aspirated (C) superior insertion is extended with a $3.2 \mathrm{~mm}$ followed by insertion of three-piece Intraocular lens (IOL) in the sulcus (D).

of the AC. Lens matter was aspirated keeping vacuum at $400 \mathrm{~mm}$ of $\mathrm{Hg}$, flow rate between 12 and $16 \mathrm{cc} / \mathrm{min}$ with an IOP ranging from 20 to $30 \mathrm{~mm} \mathrm{Hg}$ with an equivalent bottle height between $27 \mathrm{~cm}$ water and $45 \mathrm{~cm}$ water. Cut rate of $100 \mathrm{cpm}$ was used in I-A cut mode for controlled lens aspiration (figure $3 \mathrm{~B}$ ). Insertion of the irrigation probe would have deepened the chamber further with expulsion of the lens matter through the existing defect posteriorly. Irrigation probe was inserted when more than

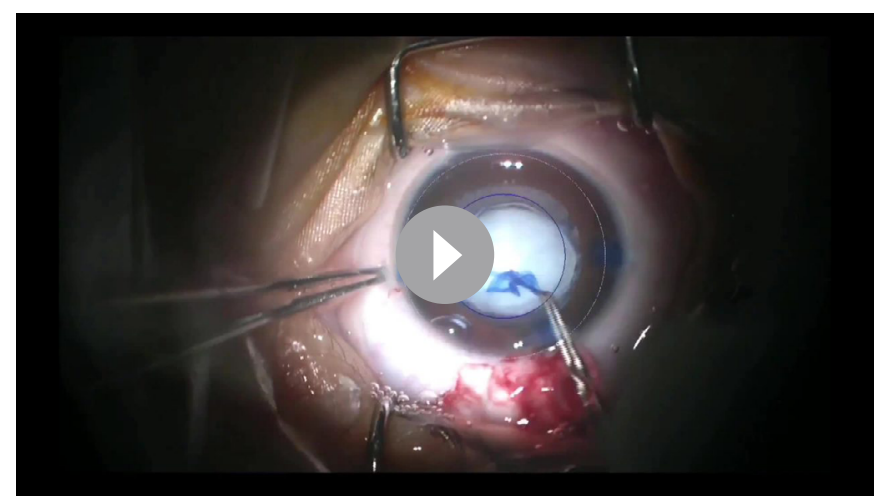

Video 1 Surgical steps of our described technique are depicted comprising of dry lens aspiration with $25 \mathrm{G}$ vitrectomy cutter in irrigation-aspiration/cutter mode without insertion of the irrigation probe followed by insertion of irrigation probe once three-fourth of the volume of lens is aspirated.

\section{Patient's perspective}

I was happy with my child's post operative outcome.The imaging helped me to understand the problem better.

Learning points

- The presence of posterior capsular abnormalities require expertise and skill to diagnose the defect preoperatively and plan accordingly.

- Ultrasound biomicroscopy imaging at a resolution of $35 \mathrm{MHz}$ is a better modality to detect posterior capsular abnormalities than B scan ultrasonography.

- Controlled lens aspiration can be performed using dry lens aspiration technique without causing turbulence in the anterior chamber.

three-fourth volume of the lens matter was aspirated (figure 3C). Anterior vitrectomy was performed $2 \mathrm{~mm}$ behind and beyond the edges of the posterior capsular defect with a cut rate of $4000 \mathrm{cpm}$.Intraoperative fundus assessment was performed in all the cases using a $25 \mathrm{G}$ endoilluminator (routinely used for vitreo retinal surgeries) inserted through one of the self-sealing corneal side ports after filling the bag with viscoelastic to visualise the fundus intraoperatively and prognosticate the visual outcome as well as to look for any lens drop posteriorly. Video 1 depicts the steps of the surgical technique in details.

To conclude, preoperative UBM imaging, avoiding hydrodissection and performing dry lens aspiration with vitrectomy cutter in I-A cut mode have the advantage of performing controlled lens aspiration through the limbal route, avoiding the need for pars plana lensectomy.

Contributors SK has performed the surgeries. MB has worked up the case and prepared the manuscript. SSR has done a literature review and helped in the preparation of manuscript. SK has retrieved the images.

Funding The authors have not declared a specific grant for this research from any funding agency in the public, commercial or not-for-profit sectors.

Competing interests None declared.

Patient consent for publication Obtained.

Provenance and peer review Not commissioned; externally peer reviewed.

\section{ORCID iD}

Mousumi Banerjee http://orcid.org/0000-0003-4346-246X

\section{REFERENCES}

1 Vasavada AR, Praveen MR, Nath V, et al. Diagnosis and management of congenital cataract with preexisting posterior capsule defect. J Cataract Refract Surg 2004;30:403-8

2 Vajpayee RB, Angra SK, Honavar SG, et al. Pre-existing posterior capsule breaks from perforating ocular injuries. J Cataract Refract Surg 1994;20:291-4.

3 Khokhar SK. Atlas of pediatric cataract. Springer, 2019.

4 Fridman G, Rizzuti AE, Liao J, et al. Trypan blue as a surgical adjunct in pediatric cataract surgery. J Cataract Refract Surg 2016;42:1774-8.

5 Saini JS, Jain AK, Sukhija J, et al. Anterior and posterior capsulorhexis in pediatric cataract surgery with or without trypan blue dye: randomized prospective clinical study. J Cataract Refract Surg 2003;29:1733-7.

6 Wilson ME. Anterior lens capsule management in pediatric cataract surgery. Trans Am Ophthalmol Soc 2004;102:391-422. 
Copyright 2021 BMJ Publishing Group. All rights reserved. For permission to reuse any of this content visit https://www.bmj.com/company/products-services/rights-and-licensing/permissions/

BMJ Case Report Fellows may re-use this article for personal use and teaching without any further permission.

Become a Fellow of BMJ Case Reports today and you can:

- Submit as many cases as you like

- Enjoy fast sympathetic peer review and rapid publication of accepted articles

Access all the published articles

Re-use any of the published material for personal use and teaching without further permission

Customer Service

If you have any further queries about your subscription, please contact our customer services team on +44 (0) 2071111105 or via email at support@bmj.com.

Visit casereports.bmj.com for more articles like this and to become a Fellow 